\section{Long-term clinical course and visual outcome associated with Peters' anomaly}

\begin{abstract}
Purpose To investigate the long-term clinical course and visual outcomes of Peters' anomaly cases treated with various treatment modalities.

Patients and Methods All patients with Peters' anomaly treated at Seoul National University Children's Hospital from 1985 to 2005 were reviewed retrospectively. Patients who were followed for more than 5 years after the first visit were enrolled for analysis of the visual outcome. Final visual outcomes were presented with respect to disease severity and treatment modalities. Disease severity was determined according to the corneal status and accompanied eye anomalies in mild or severe form. Treatment plans were classified into the following groups: (1) a medical treatment group;

(2) a surgical treatment group; and

(3) a no-treatment group.
\end{abstract}

Results A total of 106 eyes in 76 patients were diagnosed as Peters' anomaly, and 90 eyes in 65 patients were analysed regarding the visual outcome. Overall, 60 eyes (67\%) had severe disease, and 30 eyes (33\%) had mild disease. Twenty-six eyes $(29 \%)$ received medical treatment, 44 eyes $(49 \%)$ received surgical treatment, and 20 eyes (22\%) received no treatment. The mean final visual acuity was $1.415 \log$ MAR, $2.344 \log$ MAR, and $2.282 \log M A R$, respectively. The visual outcomes of the eyes with mild disease in each group were significantly better than the eyes with severe disease.

Conclusions The long-term visual outcomes of Peters' anomaly differed according to the disease severity in each treatment group. Therefore, before making treatment plans for Peters' anomaly, it is important to investigate the corneal status and accompanying eye disease to determine disease severity.
Eye (2012) 26, 1237-1242; doi:10.1038/eye.2012.128; published online 29 June 2012

Keywords: cornea opacity; eye abnormalities; follow-up studies; prognosis; treatment outcome; visual acuity

\section{Introduction}

Peters' anomaly was first described in 1906 as a congenital anomaly of the anterior segment of the eye. ${ }^{1}$ It is characterised by central corneal opacity with corresponding defects in the posterior stroma, Descemet's membrane, and endothelium. ${ }^{2-5}$ Another characteristic is that the iris strands frequently extend from the collarette to the posterior border of the corneal leukoma. ${ }^{3-7}$ The central corneal opacity of Peters' anomaly is so dense that it can prevent infants from improving their vision. Penetrating keratoplasty (PKP) is performed to eliminate corneal opacity, but the decision to perform PKP is not easy because not only is the rate of graft failure higher but also postoperative care in children is difficult. However, as the degree of corneal opacity varies so widely and various ophthalmic anomalies are present, the treatment protocol used can differ in each case of Peters' anomaly. Previous studies of Peters' anomaly cases were mainly focused on surgical outcomes following PKP. ${ }^{8-14}$

However, this study was designed to investigate the long-term clinical course and report the visual outcomes in Peters' anomaly patients treated with various treatment modalities.

Patients and methods

\section{Ophthalmic and systemic evaluation}

This study was approved by the Seoul National University Hospital Institutional Review Board.
'Department of Ophthalmology, Inje University, Ilsan Paik Hospital, Goyang, Korea

${ }^{2}$ Department of Ophthalmology, Seoul National University Children's Hospital, Seoul, Korea

${ }^{3}$ Seoul Artificial Eye Center, Seoul National University Hospital Clinical Research Institute, Seoul, Korea

Correspondence: YS Yu, Department of Ophthalmology, Seoul National University Children's Hospital, 28, Yeongeon-Dong, Seoul, Jongno-Gu 110-744, Korea Tel: +82 22072 3492; Fax: +82 27413187 . E-mail: ysyu@snu.ac.kr

Received: 9 December 2011 Accepted in revised form: 7 May 2012 Published online: 29 June 2012 
Detailed medical records for all patients who were diagnosed as having Peters' anomaly at Seoul National University Hospital from 1985 to 2005 were reviewed retrospectively. The ophthalmic evaluations performed at the initial presentation included a slit-lamp examination of the anterior segments, an intraocular pressure (IOP) measurement, and a fundus examination with an indirect ophthalmoscope or ultrasonography, if the fundus was invisible. To evaluate the long-term visual outcome, a subgroup analysis was performed with the patients who were diagnosed with Peters' anomaly and followed up for more than 5 years. For systemic work-ups, patients were referred to a paediatrician to identify any systemic anomaly. We also compared the final visual outcomes of those patients with accompanying systemic anomalies and those with none. All final visual acuities were measured using the Snellen visual acuity chart and converted to $\log$ MAR for statistical analysis

\section{Disease severity}

Disease severity was classified into two categories: mild and severe disease. We defined the eyes as having mild disease if the size of the cornea was normal and/or there was corneal opacity over less than half of the cornea, iridocorneal adhesion, or any other accompanying iris abnormality. However, the eyes were categorised as severely diseased if there was corneal opacity over more than half of the cornea, corneo-lenticular adhesion, corneal staphyloma, or an associated ophthalmic anomaly such as microphthalmia, persistent hyperplastic primary vitreous (PHPV), aniridia, or cataracts.

\section{Treatment modalities}

The eyes with Peters' anomaly were classified into three groups according to the treatment protocol: (1) the medical treatment group, (2) the surgical treatment group, and (3) the no-treatment group. Medical treatment was attempted when the media opacity was not too dense to allow for fundus examination. The medical treatment was comprised of occlusion therapy with or without pupil dilation with mydriatics. The indication for amblyopia treatment was any case of unilateral disease or bilateral disease that involved visual asymmetry between the eyes. However, if the media opacity was too dense to observe the fundus, various additional surgical treatments were performed. In this study, the surgical treatments used included the following: (1) optical-sector iridectomy, (2) PKP, (3) cataract surgery, and (4) trabeculectomy. Sometimes multiple surgical methods were performed simultaneously or individually. The surgical method used to treat each eye was determined according to the status of the cornea, the lens and other associated anomalies of the eye. To improve vision, optical-sector iridectomy, which dilates the pupil by surgical incision of the pupillary sphincter, was performed. PKP was performed if the cornea opacity was too dense for optical-sector iridectomy alone to improve vision. Cataract surgery was performed when the lens opacity was considered to disrupt vision development. Trabeculectomy was performed when all glaucoma medications administered failed to lower IOP. The final visual outcomes of all the surgical treatment groups were presented. Cases in which no treatment was available were placed in the no-treatment group.

\section{Statistical methods}

We used SPSS software, version 17.0 (SPSS Inc., Chicago, IL, USA) for all statistical analyses. All tests were twotailed, and significance was set at 0.05 . Final visual acuity was compared among the medical treatment group, the surgical treatment group, and the no-treatment group. The distribution of visual acuity between groups was analysed by one-way analysis of variance (ANOVA). The final visual outcome was compared according to the treatment modality used, the laterality of the disease, and the disease severity with multiple linear regression analysis. Conversion of Snellen visual acuity to logMAR was performed according to the method proposed by Holladay. ${ }^{15}$ To compare final visual outcomes, assessments of light perception (LP) and no light perception (NLP) were included in analysis of the data as Schulze-Bounsel et al ${ }^{16}$ proposed, LP was assigned to a $\log$ MAR value of 2.7 and NLP to a $\log$ MAR value of 3.0.

\section{Results}

\section{Ophthalmic and systemic features}

One hundred and six eyes in 76 patients were diagnosed as having Peters' anomaly during the study period. Forty-six patients $(61 \%)$ had unilateral disease, and 30 patients $(39 \%)$ had bilateral disease. For evaluating the visual outcome, 90 eyes in 65 patients who were followed up for more than 5 years were enrolled, and 16 eyes of 11 patients were excluded because of insufficient follow-up in this study (Table 1). The average final visual acuity of all enrolled patients was $2.049 \pm 0.965 \log$ MAR (20/2240), and there was no significant difference between the unilateral $(2.054 \pm 0.974 \log$ MAR) and bilateral (2.046 $\pm 0.967 \log \mathrm{MAR})$ disease groups (independent t-test, $P=0.969)$.

Among the total 76 patients, 22 patients (29\%) had accompanying systemic anomalies. Eight patients in the bilateral disease group and 13 patients in the unilateral 
Table 1 Demographic characteristics of the total, enrolled and excluded patients with Peters' anomaly

\begin{tabular}{|c|c|c|c|c|}
\hline & $\begin{array}{c}\text { Total } \\
\text { patients }\end{array}$ & $\begin{array}{l}\text { Enrolled } \\
\text { patients }^{\mathrm{a}}\end{array}$ & $\begin{array}{c}\text { Excluded } \\
\text { patients }\end{array}$ & P-value \\
\hline $\begin{array}{l}\text { Eyes / } \\
\text { Patients }\end{array}$ & $106 / 76$ & $90 / 65$ & $16 / 11$ & \\
\hline Gender & & & & $0.576^{c}$ \\
\hline Male & $36(47.4 \%)$ & $31(47.7 \%)$ & $5(45.5 \%)$ & \\
\hline Female & $40(52.6 \%)$ & $34(52.3 \%)$ & $6(54.5 \%)$ & \\
\hline \multicolumn{4}{|c|}{ Laterality (patients) } & $0.452^{\mathrm{c}}$ \\
\hline Unilateral & $46(60.5 \%)$ & $40(61.5 \%)$ & $6(54.5 \%)$ & \\
\hline Bilateral & $30(39.5 \%)$ & $25(38.5 \%)$ & $5(45.5 \%)$ & \\
\hline $\begin{array}{l}\text { Systemic } \\
\text { anomaly } \\
\text { (patients) }\end{array}$ & $22(28.9 \%)$ & $19(29.2 \%)$ & $3(27.3 \%)$ & $0.603^{c}$ \\
\hline Unilateral & 13 & 12 & 1 & \\
\hline Bilateral & 9 & 7 & 2 & \\
\hline $\begin{array}{l}\text { Age at } \\
\text { presentation } \\
\text { (months) }\end{array}$ & $\begin{array}{c}\text { Mean: } \\
7.7 \pm 22.3 \\
\text { Median: } \\
1.0(0-125)\end{array}$ & $\begin{array}{c}\text { Mean: } \\
6.5 \pm 18.8 \\
\text { Median: } \\
1.0(0-122)\end{array}$ & $\begin{array}{c}\text { Mean: } \\
15.4 \pm 37.1 \\
\text { Median: } \\
1.0(0-125)\end{array}$ & $0.221^{\mathrm{d}}$ \\
\hline $\begin{array}{l}\text { Follow-up } \\
\text { period } \\
\text { (months) }\end{array}$ & $\begin{array}{c}\text { Mean: } \\
90.3 \pm 62.6 \\
\text { Median: } \\
81.5(0-280)\end{array}$ & $\begin{array}{c}\text { Mean: } \\
104.2 \pm 56.5 \\
\text { Median: } \\
93 \text { (60-280) }\end{array}$ & $\begin{array}{c}\text { Mean: } \\
5.8 \pm 5.9 \\
\text { Median: } \\
6.0(0-16)\end{array}$ & $<0.001^{\mathrm{d}}$ \\
\hline
\end{tabular}

${ }^{\mathrm{a}}$ For evaluation of visual outcome.

${ }^{\mathrm{b}}$ Comparison between the enrolled group and the excluded group.

'Fisher's exact test.

${ }^{\mathrm{d}}$ Independent samples $t$-test.

Table 2 Associated systemic anomalies of the total sample of Peters' anomaly patients $(n=76)$

\begin{tabular}{lccc}
\hline & $\begin{array}{c}\text { Unilateral } \\
\text { Peters' } \\
\text { anomaly }\end{array}$ & $\begin{array}{c}\text { Bilateral } \\
\text { Peters } \\
\text { anomaly }\end{array}$ & $\begin{array}{c}\text { Sum } \\
\text { (\% of total } \\
\text { patients) }\end{array}$ \\
\hline Developmental delay & 6 & 4 & $10(13.2 \%)$ \\
Cardiopulmonary anomaly & 4 & 4 & $8(10.5 \%)$ \\
Musculoskeletal anomaly & 2 & 3 & $5(6.6 \%)$ \\
Gastrointestinal anomaly & 3 & 2 & $5(6.6 \%)$ \\
Urogenital anomaly & 3 & 0 & $3(3.9 \%)$ \\
Central nervous system anomaly & 1 & 1 & $2(2.6 \%)$ \\
Ear anomaly & 1 & 0 & $1(1.3 \%)$ \\
Total $^{\text {a }}$ & 13 & 9 & $22(28.9 \%)$ \\
\hline
\end{tabular}

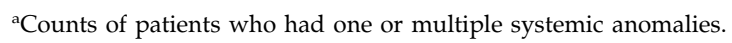

disease group had associated systemic anomalies, although laterality and systemic anomalies had no significant association (Pearson's $\chi^{2}$ test, $P=0.870$ ). The most frequent accompanying anomaly (in 10 of 22 patients) was developmental delay. Cardiopulmonary anomaly was the second most frequent accompanying anomaly (Table 2). The average final visual acuity of the associated systemic anomaly group $(2.245 \pm 0.917$ $\log$ MAR) was not significantly different from that of the group with no associated anomalies $(1.918 \pm 1.010$ $\log$ MAR) (independent $t$-test, $P=0.168$ ).

\section{Disease severity and treatment modalities}

Of the enrolled patients for evaluating the visual outcome, 60 eyes $(67 \%)$ were categorised as having severe disease, and 30 eyes (33\%) were categorised as having mild disease. The most common cause of severe disease was corneal opacity over more than half of the cornea and microphthalmos. Congenital cataract and aniridia were followed. However, there was no significant association between the laterality of the disease and the disease severity (Pearson's $\chi^{2}$ test, $P=0.516)$ or between the laterality of the disease and the treatment modality (Pearson's $\chi^{2}$ test, $P=0.243$ ) (Table 3 ).

Twenty-six eyes (29\%) received medical treatment, 44 eyes $(49 \%)$ received surgical treatment, and 20 eyes (22\%) received no treatment. The mean final visual acuities of the medical, surgical and no-treatment groups were $1.415 \pm 1.033,2.344 \pm 0.798$ and $2.282 \pm 0.894 \log$ MAR, respectively. The average final visual acuity differed significantly among the treatment groups (one-way ANOVA, $P<0.001)$. Detailed data on the final visual results for each treatment group, subdivided by the disease severity, are shown in Figure 1. In the medical treatment group, the final visual acuities in the mild and severe disease groups were $0.789 \pm 0.738$ and $2.042 \pm 0.910 \log$ MAR, respectively. Approximately half of the eyes with mild disease had visual acuity of 20/100 or better, whereas more than half of eyes with severe disease had visual acuity categorised as finger-counting (CF) or worse. In the surgical treatment group, the final visual acuities in the mild and severe disease groups were $1.784 \pm 0.909$ and $2.543 \pm 0.606 \log$ MAR, respectively. Thirty-six per cent of the eyes with mild disease had a visual acuity of 20/400 or better, while $93 \%$ of eyes with severe disease were categorised as having CF or worse, and $52 \%$ were classified as having NLP. We surveyed the outcomes associated with various surgical treatments, and the final visual outcomes are presented in Table 4 . The mean age when the first surgical treatment was performed was $22.18 \pm 30.15$ months (range, 1-147 months). However, there was no significant correlation between the age of the first surgical treatment and the final visual outcome (simple linear regression, $P=0.255)$. In the no-treatment group, the final visual acuities in the mild and severe disease groups were $1.449 \pm 0.986$ and $2.731 \pm 0.395 \log$ MAR, respectively. Although $43 \%$ of the eyes with mild disease had a visual acuity of 20/400 or better, all eyes with severe disease were categorised as CF or worse, and $62 \%$ of the eyes with severe disease were categorised as having NLP. 
Table 3 Number of eyes according to the causes of severe disease

\begin{tabular}{|c|c|c|c|c|}
\hline & $\begin{array}{c}\text { Medical } \\
\text { treatment } \\
(\mathrm{n}=26)\end{array}$ & $\begin{array}{c}\text { Surgical } \\
\text { treatment } \\
(\mathrm{n}=44)\end{array}$ & $\begin{array}{c}\text { No } \\
\text { treatment } \\
(\mathrm{n}=20)\end{array}$ & $\begin{array}{c}\text { Total } \\
(\mathrm{n}=90)\end{array}$ \\
\hline $\begin{array}{l}\text { Opacity over more } \\
\text { than half of the cornea }\end{array}$ & 6 & 15 & 4 & 25 \\
\hline $\mathrm{U}$ & 1 & 6 & 4 & 11 \\
\hline B & 5 & 9 & 0 & 14 \\
\hline $\begin{array}{l}\text { Corneo-lenticular } \\
\text { adhesion }\end{array}$ & 0 & 5 & 0 & 5 \\
\hline $\mathrm{U}$ & 0 & 0 & 0 & 0 \\
\hline $\mathrm{B}$ & 0 & 5 & 0 & 5 \\
\hline Corneal staphyloma & 1 & 5 & 1 & 7 \\
\hline U & 0 & 1 & 0 & 1 \\
\hline $\mathrm{B}$ & 1 & 4 & 1 & 6 \\
\hline Microphthalmos & 6 & 9 & 9 & 24 \\
\hline U & 4 & 6 & 3 & 13 \\
\hline B & 2 & 3 & 6 & 11 \\
\hline$P H P V^{a}$ & 1 & 0 & 0 & 1 \\
\hline U & 0 & 0 & 0 & 0 \\
\hline B & 1 & 0 & 0 & 1 \\
\hline Aniridia & 0 & 7 & 3 & 10 \\
\hline U & 0 & 0 & 0 & 0 \\
\hline B & 0 & 7 & 3 & 10 \\
\hline Cataract & 1 & 13 & 2 & 16 \\
\hline U & 0 & 4 & 0 & 4 \\
\hline B & 1 & 9 & 2 & 12 \\
\hline Iris cyst & 0 & 1 & 0 & 1 \\
\hline $\mathrm{U}$ & 0 & 1 & 0 & 1 \\
\hline B & 0 & 0 & 0 & 0 \\
\hline Total & $13(50 \%)^{\mathrm{a}}$ & $34(77 \%)^{\mathrm{a}}$ & $13(65 \%)^{\mathrm{a}}$ & $60(67 \%)^{\mathrm{b}}$ \\
\hline U & 5 & 16 & 5 & 26 \\
\hline B & 8 & 18 & 8 & 34 \\
\hline
\end{tabular}

Abbreviations: B, bilateral Peters' anomaly; PHPV, persistent hyperplastic primary vitreous; $\mathrm{U}$, unilateral Peters' anomaly.

aPercentage of eyes with one or multiple causes of severe disease in each treatment group.

${ }^{b}$ Percentage of eyes with one or multiple causes of severe disease in enrolled eyes.

The final visual acuity of the eyes with mild disease was significantly better in each treatment group (Mann-Whitney test, $P<0.05)$. However, there was no significant difference in the final visual acuity according to the laterality of the disease in each treatment group (Mann-Whitney test, $P>0.05)$. The final visual outcome was influenced significantly by the treatment modalities (multiple linear regression, $P=0.001$ ) and disease severity (multiple linear regression, $P<0.001$ ). However, the laterality of the disease had no significant influence on the final visual outcome (multiple linear regression, $P=0.311$ ).
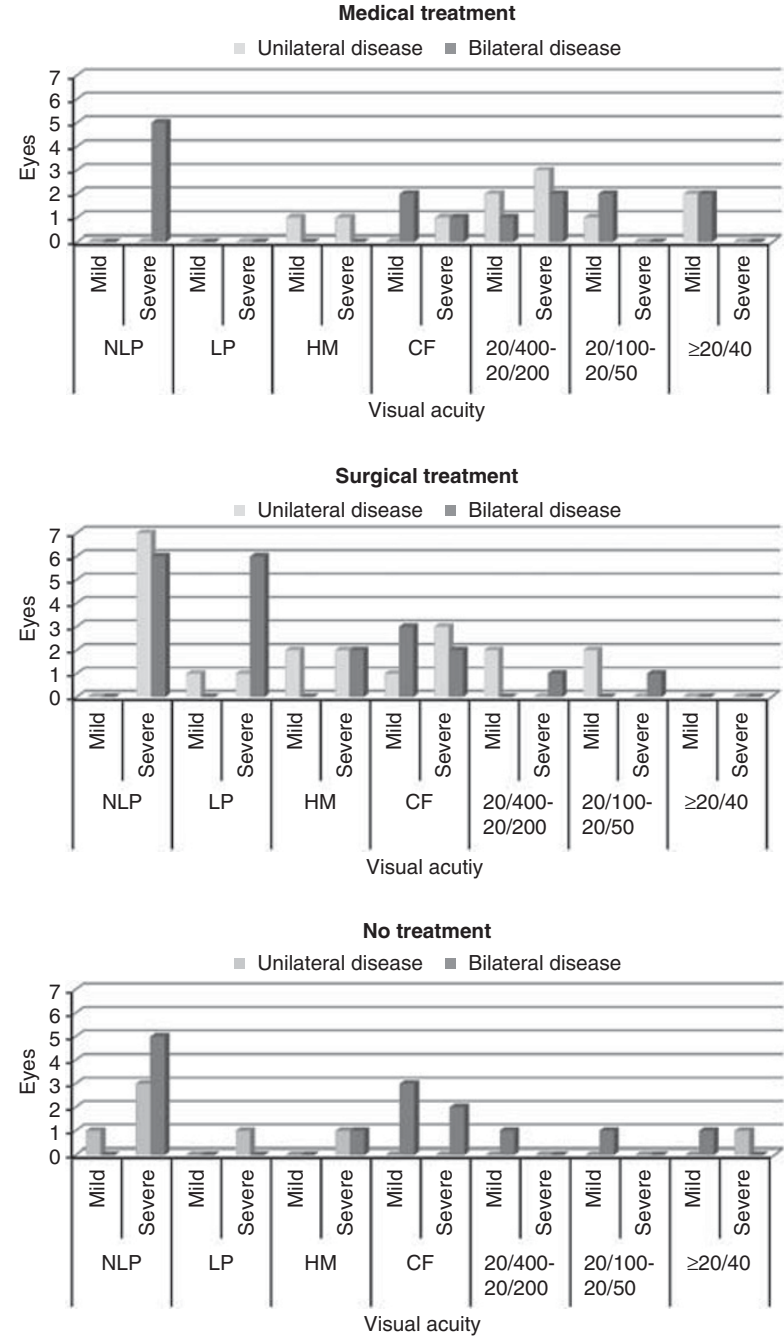

Figure 1 Visual outcome of each treatment group.

\section{Discussion}

This study aimed to investigate the treatment modalities of Peters' anomaly cases, and how visual outcomes differed among various levels of disease severity and treatment methods. Peters' anomaly was classically classified as type I, type II, or Peters' plus syndrome. The original definition of Peters' anomaly, expressed as type I or type II, is determined by the presence of lens opacity or corneo-lenticular adhesion. Peters' plus syndrome is defined by the coexistence of various systemic anomalies. These classifications were not sufficient to reflect the status of Peters' anomaly or predict the visual outcome because Peters' anomaly was frequently accompanied by other ophthalmic anomalies that could influence the visual outcome. There were only 16 eyes with type II Peters' anomaly with cataract (16 eyes) and corneolenticular adhesion (5 eyes with also cataract) in this study, although another 43 eyes had other accompanying 
Table 4 Comparisons of visual outcomes after each treatment modality

\begin{tabular}{|c|c|c|c|c|c|c|c|}
\hline & $\begin{array}{l}\text { PKP only } \\
(\mathrm{n}=18)\end{array}$ & $\begin{array}{l}\text { PKP with } \\
C A T(\mathrm{n}=3)\end{array}$ & $\begin{array}{l}\text { OSI followed by } \\
\operatorname{PKP}(\mathrm{n}=2)\end{array}$ & $\begin{array}{l}\text { OSI followed by PKP } \\
\text { and CAT }(\mathrm{n}=1)\end{array}$ & $\begin{array}{l}\text { OSI only } \\
(\mathrm{n}=6)\end{array}$ & $\begin{array}{l}\text { CAT only } \\
(\mathrm{n}=8)\end{array}$ & $\begin{array}{l}\text { TRA } \\
(\mathrm{n}=6)\end{array}$ \\
\hline NLP & 7 & 1 & 0 & 0 & 2 & 2 & 6 \\
\hline LP & 4 & 1 & 0 & 0 & 0 & 1 & 0 \\
\hline $\mathrm{HM}$ & 1 & 0 & 0 & 1 & 2 & 2 & 0 \\
\hline $\mathrm{CF}$ & 3 & 1 & 2 & 0 & 0 & 2 & 0 \\
\hline $20 / 400-20 / 200$ & 3 & 0 & 0 & 0 & 0 & 0 & 0 \\
\hline $20 / 100-20 / 50$ & 0 & 0 & 0 & 0 & 2 & 1 & 0 \\
\hline$\geq 20 / 40$ & 0 & 0 & 0 & 0 & 0 & 0 & 0 \\
\hline
\end{tabular}

Abbreviations: CAT, cataract surgery; OSI, optical sector iridectomy; PKP, penetrating keratoplasty; TRA, trabeculectomy.

ophthalmic anomalies that can affect the visual outcome. Therefore, we introduced new classification in this study. We included all eyes with Peters' anomaly and divided the groups according to the disease severity and treatment modality so that we could evaluate the clinical course and focus on the visual outcome, not just of surgical treatment (especially PKP), but also of all the treatment methods applied to the patients. The incidence of severe disease was not significantly different between the unilateral and bilateral disease groups (Pearson's $\chi^{2}$ test, $P=0.516$ ), and it was not associated with accompanying systemic anomaly (Pearson's $\chi^{2}$ test, $P=0.806$ ), which indicated that the incidence of severe disease was not significantly associated with the laterality of the disease or the presence of accompanying systemic anomaly. In addition, according to the classical classification, the incidence of type I or II Peters' anomaly was not significantly different according to the laterality of the disease (Fisher's exact test, $P=0.102$ ) or the presence of accompanying systemic anomaly (Fisher's exact test, $P=0.125$ ).

The average final visual acuity of Peters' anomaly cases was $2.049 \pm 0.965 \log$ MAR $(20 / 2240)$. The final visual acuity in each group differed according to both treatment modality and disease severity. The disease severity of Peters' anomaly before any treatment was the factor that contributed most strongly to final visual outcome. Among all treatment groups, the average final visual acuity in the medical treatment group was better than the outcomes for the other groups. This does not mean that medical treatment was a superior treatment method; rather, more severe cases of Peters' anomaly have a tendency to undergo surgical treatments (Pearson's $\chi^{2}$ test, $\left.P=0.019\right)$. Twenty-four eyes from 23 children in this study underwent PKP. The final visual outcomes of PKP with mild disease were better than the outcomes of PKP with severe disease. There was a subsignificant relationship between disease severity and the visual outcomes of PKP (Mann-Whitney test, $P=0.055$ ). Among the various treatment modalities, optical-sector iridectomy was effective in allowing the eye to receive more visual stimulation through the widened pupil. Jünemann et al ${ }^{17}$ published the outcomes of optical-sector iridectomies performed in 13 patients in 1996 for the first time; $47 \%$ of the eyes had visual acuities ranging from $20 / 500$ to $20 / 200$. The authors recommended the procedure as a surgical alternative to early PKP, but until this study, no other report made the same recommendation. Six eyes in this study that underwent optical-sector iridectomy had visual acuities of approximately $1.987 \log$ MAR (20/1940), and 50\% had vision that was categorised as better than CF. Although the number of eyes compared was small, there was no significant difference between the visual outcomes of optical-sector iridectomy and PKP (Mann-Whitney test, $P=0.519$ ). Optical-sector iridectomy is easier to perform and is associated with a reduced rate of complications compared with PKP. Therefore, optical-sector iridectomy is considered as a solitary treatment modality and an alternative therapeutic option in selected cases. This procedure could also be performed before PKP to allow more time to evaluate an increase in the rate of graft survival.

Fourteen eyes (16\%) had associated glaucoma, and six of these eyes (43\%) required trabeculectomy because IOP could not be controlled using eye drops. Among the six eyes requiring trabeculectomy, five had bilateral disease, and four had severe disease. The major postoperative complications were retinal detachment (three eyes) and phthisis (two eyes). All of the eyes that underwent trabeculectomy had final vision categorised as NLP. Although direct comparison was impossible because the previous study did not report the visual results of each surgical procedure, the overall results of trabeculectomy were worse than those found in a previous study by Yang et al. ${ }^{18}$ We were unable to provide a valid statistical analysis of the glaucoma treatment because of the small number of eyes undergoing the procedure. It is likely that trabeculectomy in Peters' anomaly cases with severe disease was associated with inferior prognosis.

Twenty-two patients (29\%) had associated systemic anomalies. The most common systemic anomaly was 
developmental delay, which is similar to the findings of Yang et al ${ }^{11}(38 \%)$ and Ozeki et al ${ }^{19}$ (35\%) in Japanese patients. The final visual outcomes did not differ between patients with associated systemic anomalies and patients with no associated anomaly. However, among the patients with associated systemic anomaly, the unilateral group displayed better outcomes than the bilateral group, but the difference was not statistically significant (Mann-Whitney test, $P=0.148$ ).

In conclusion, the most important factor determining treatment method and visual outcome was disease severity. The incidence of disease severity was not associated with the laterality or the association of systemic anomaly. If there was corneal opacity over more than half of the cornea, corneo-lenticular adhesion, corneal staphyloma or an associated ophthalmic anomaly such as microphthalmia, PHPV, aniridia or cataract, the visual outcome was worse-regardless of treatment modality. Therefore, it is important to discover any combined eye anomaly present in association with Peters' anomaly before making treatment plans.

The major limitation of this study is that a selection bias may have been created by the methodology used to group the patients. Another limitation was the retrospective design of the study. Therefore, we could not compare the visual outcomes of eyes with the same condition between the treatment modalities. Despite these potential limitations, we evaluated all treatment methods applied to the Peters' anomaly patients and found that visual outcomes differed according to disease severity in each treatment group.

\section{Summary}

What was known before

- There was not much data about visual outcome of Peters' anomaly after long-term follow-up. Some papers reported surgical result after PKP. However, with other treatment methods, the visual outcome after long-term follow-up was hard to find.

What this study adds

- We investigated whole cases of Peters' anomaly and divided the groups according to the treatment modalities. We compared the visual outcome of each group after long-term follow-up. Especially we found out that the eyes with severe disease defined as having accompanied other congenital ophthalmic anomaly had worse prognosis. After revision, we added more information about correlation between the disease status and various outcomes.

\section{Conflict of interest}

The authors declare no conflict of interest.

\section{References}

1 Chan CC, Holland EJ. Cataract surgery after keratolimbal allograft surgery in patients with congenital aniridia. J Cataract Refract Surg 2011; 37: 786-787.

2 Nakanishi I, Brown SI. The histopathology and ultrastructure of congenital, central corneal opacity (Peters' anomaly). Am J Ophthalmol 1971; 72: 801-812.

3 Waring 3rd GO, Rodrigues MM, Laibson PR. Anterior chamber cleavage syndrome. A stepladder classification. Surv Ophthalmol 1975; 20: 3-27.

4 Kenyon KR. Mesenchymal dysgenesis in Peter's anomaly, sclerocornea and congenital endothelial dystrophy. Exp Eye Res 1975; 21: 125-142.

5 Stone DL, Kenyon KR, Green WR, Ryan SJ. Congenital central corneal leukoma (Peters' anomaly). Am J Ophthalmol 1976; 81: 173-193.

6 Reese AB, Ellsworth RM. The anterior chamber cleavage syndrome. Arch Ophthalmol 1966; 75: 307-318.

7 Townsend WM, Font RL, Zimmerman LE. Congenital corneal leukomas. 2. Histopathologic findings in 19 eyes with central defect in Descemet's membrane. Am J Ophthalmol 1974; 77: 192-206.

8 Huang C, O'Hara M, Mannis MJ. Primary pediatric keratoplasty: indications and outcomes. Cornea 2009; 28 : 1003-1008.

9 Rao KV, Fernandes M, Gangopadhyay N, Vemuganti GK, Krishnaiah S, Sangwan VS. Outcome of penetrating keratoplasty for Peters anomaly. Cornea 2008; 27: 749-753.

10 Yang LL, Lambert SR, Drews-Botsch C, Stulting RD. Long-term visual outcome of penetrating keratoplasty in infants and children with Peters anomaly. J AAPOS 2009; 13: $175-180$.

11 Yang LL, Lambert SR, Lynn MJ, Stulting RD. Long-term results of corneal graft survival in infants and children with peters anomaly. Ophthalmology 1999; 106: 833-848.

12 Zaidman GW, Flanagan JK, Furey CC. Long-term visual prognosis in children after corneal transplant surgery for Peters anomaly type I. Am J Ophthalmol 2007; 144: 104-108.

13 Lowe MT, Keane MC, Coster DJ, Williams KA. The outcome of corneal transplantation in infants, children, and adolescents. Ophthalmology 2011; 118: 492-497.

14 Basdekidou C, Dureau P, Edelson C, De Laage De Meux P, Caputo G. Should unilateral congenital corneal opacities in Peters' anomaly be grafted? Eur J Ophthalmol 2011; 21: 695-699.

15 Holladay JT. Proper method for calculating average visual acuity. J Refract Surg 1997; 13: 388-391.

16 Schulze-Bonsel K, Feltgen N, Burau H, Hansen L, Bach M. Visual acuities 'hand motion' and 'counting fingers' can be quantified with the freiburg visual acuity test. Invest Ophthalmol Vis Sci 2006; 47: 1236-1240.

17 Jünemann A, Gusek GC, Naumann GO. Optical sector iridectomy: an alternative to perforating keratoplasty in Peters' anomaly. Klin Monbl Augenheilkd 1996; 209: 117-124.

18 Yang LH, Lambert SR, Lynn MJ, Stulting RD. Surgical management of glaucoma in infants and children with Peters' anomaly: long-term structural and functional outcome. Ophthalmology 2004; 111: 112-117.

19 Ozeki H, Shirai S, Nozaki M, Sakurai E, Mizuno S, Ashikari M et al. Ocular and systemic features of Peters' anomaly. Graefes Arch Clin Exp Ophthalmol 2000; 238: 833-839. 